\title{
Defect-mediated Jahn-Teller effect in layered $\mathrm{LiNiO}_{2}$
}

\author{
Weicheng Lin ${ }^{1 \dagger}$, Yaokun Ye ${ }^{1 \dagger}$, Taowen Chen ${ }^{1}$, Yao Jiang ${ }^{2}$, Chuying Ouyang ${ }^{2}$, Feng Pan ${ }^{*}$ and \\ Jiaxin Zheng ${ }^{1,2^{*}}$
}

$\mathrm{Ni}$-rich layered lithium transition metal oxide materials, such as $\mathrm{LiNi}_{1-x-y} \mathrm{Mn}_{x} \mathrm{Co}_{y} \mathrm{O}_{2}$ (NMC) and $\mathrm{LiNi}_{1-x-y} \mathrm{Co}_{x} \mathrm{Al}_{y} \mathrm{O}_{2}$ (NCA), are used as cathode materials in lithium-ion batteries [1-4]. Improvements in the energy density and reductions in Co cost can be achieved by increasing the $\mathrm{Ni}$ content so that the compositions of these two materials invariably converge toward $\mathrm{LiNiO}_{2}$ (LNO). Recently, LNO has attracted increased attention for compositional designs of next-generation low-/zero-Co, ultrahigh-Ni layered oxides as alternatives to NMC/NCA. However, the crystallographic and electronic structures of LNO remain subjects of considerable controversy. LNO has been experimentally reported to exist in the $R \overline{3} m$ phase [5-9] and exhibit semiconductor behavior with a small band gap [10-15], while theoretical studies have reported that stoichiometric $R \overline{3} \mathrm{~m}$ LNO is a conductor and unstable [16-22]. Moreover, the Ni ions in LNO are considered as Jahn-Teller (JT)-active $\mathrm{Ni}^{3+}$ with the electronic configuration of $\mathrm{t}_{2 \mathrm{~g}}{ }^{6} \mathrm{e}_{\mathrm{g}}{ }^{1}[8,10,12,23]$. Nevertheless, extended X-ray absorption fine structure and neutron diffraction data have indicated that only local Jahn-Teller distortion (LJTD) exist [8,24-26], implying the absence of long-range collective Jahn-Teller distortion (CJTD), which is the ground state of $\mathrm{NaNiO}_{2}(\mathrm{NNO})$, a topologically equivalent compound of LNO $[23,27,28]$.

The discrepancy between the experimental and theoretical studies has been explained based on phases other than $R \overline{3} \mathrm{~m}$ [22,29-31], building possible orbital ordering patterns $[8,21,30,32]$, defective structures [33-35], time and ordering averages of dynamic stabilization [29,36], and combining theoretical methods [16-20,22,37]; however, few such studies have provided sufficient explanations. The most plausible explanation for this discrepancy was provided by Petit et al. [33]. They established an extra-Ni-based model with a $\sim 1 \mathrm{eV}$ band gap by substituting $25 \%$ of $\mathrm{Li}^{+}$with $\mathrm{Ni}^{2+}$ using the self-interactioncorrected local-spin-density method [33]. However, this band gap is extremely large compared with the experimental data of $\sim 0.5 \mathrm{eV}$, and no LJTD has been reported [11-14]. Moreover, $25 \%$ of the $\mathrm{Li}$ sites occupied by $\mathrm{Ni}^{2+}$ appears far-fetched, as $\left(\mathrm{Li}_{1-x} \mathrm{Ni}_{x}\right) \mathrm{NiO}_{2}$ has been reported with an $x$ of up to 0.14 $[5,13,26,38-40]$.

In this study, we observed that when $\mathrm{Ni} / \mathrm{Li}$ antisites are considered, the discrepancy between the experimental and theoretical results of $R \overline{3} m$ LNO can be solved. Some theoretical and experimental studies have confirmed the existence of $\mathrm{Ni} / \mathrm{Li}$ antisites in NMC [41-44] and LNO [7,34], but the focus of these studies was on the removal of $\mathrm{Ni} / \mathrm{Li}$ antisites and not on the JT effect $[45,46]$. The defect concentration of $\left(\mathrm{Li}_{1-x} \mathrm{Ni}_{x}\right)\left(\mathrm{Ni}_{1-x} \mathrm{Li}_{x}\right) \mathrm{O}_{2}$ was determined as $\sim 3 \%$ by Kanno et al. [13]. Based on hybrid density functionals of Heyd-Scuseria-Ernzerhof (HSE06) calculations, $\mathrm{LNO}$ with $\mathrm{Ni} / \mathrm{Li}$ exhibited a band gap of $0.40 \mathrm{eV}$ with LJTD, which agreed with the experimental results. Further discussion on the Kanno's model and our computational details can be found in the Supplementary information (SI) Sect. A (Fig. S1) and B.

We considered a trigonal structure $(R \overline{3} \mathrm{~m})$ comprising layers of $\mathrm{NiO}_{2}$ slabs, with edge-sharing octahedra, separated by a lithium layer (Fig. 1a). In the ideal structure, Ni ions occupy 3a sites and Li ions occupy $3 \mathrm{~b}$ sites. Two possible defective LNO types were considered (Fig. 1a): a model with extra $\mathrm{Ni}$ (the previous model, $\left.\left(\mathrm{Li}_{26} \mathrm{Ni}\right)_{3 \mathrm{~b}}\left(\mathrm{Ni}_{27}\right)_{3 \mathrm{a}} \mathrm{O}_{54}[5,7,39,40]\right)$ and a model with $\mathrm{Ni} / \mathrm{Li}$ (the model proposed herein, $\left.\left(\mathrm{Li}_{26} \mathrm{Ni}\right)_{3 \mathrm{~b}}\left(\mathrm{Ni}_{26} \mathrm{Li}\right)_{3 \mathrm{a}} \mathrm{O}_{54}\right)$. Some theoretical studies have focused on the $P 2_{1} / c$ phase as it exhibits the lowest energy of LNO among various phases [22,29-31]. However, it should be excluded owing to its inconsistency with experiments. $P 2_{1} / c$ is significantly different with $R \overline{3} m$, as reported by prior experiments [5-9]. Besides, defects were not considered in these studies, which conflicted with the fact that ideal LNO has not yet been synthesized $[5,10,13,26,47,48]$. The calculated parameters of $R \overline{3} m$ LNO $(a=b=2.896 \AA, c$ $=14.397 \AA)$ are closer to the experimental data $(a=b=2.883 \AA$, $c=14.215 \AA$ ) $[7,49]$. Although the magnetism of LNO is affected by many factors, ferromagnetic (FM) is a common approximation [9]. Therefore, we considered LNO as FM for all calculations. Its lattice parameters match with the experimental data, but $\mathrm{NiO}_{6}$ octahedra in $R \overline{3} m$ LNO have identical $\mathrm{Ni}-\mathrm{O}$ bond lengths, contradictory to the varying $\mathrm{Ni}-\mathrm{O}$ bond lengths reported via experiments $[8,24,26]$. This discrepancy would be explained based on defective models.

The density of states (DOS) of the ideal $R \overline{3} m$ LNO indicates that the empty spin-down $e_{g}$ band and half occupied spin-up $e_{g}$ band ensure the electronic configuration of $\mathrm{t}_{2 \mathrm{~g}}{ }^{6} \mathrm{e}_{\mathrm{g}}{ }^{1}$, corresponding to $\mathrm{Ni}^{3+}$ (Fig. 1b). The spin-up $\mathrm{e}_{\mathrm{g}}$ band lies on the Fermi level and exhibits a conducting behavior, which is consistent with the previous theoretical studies and contrary to the experimental semiconductor behavior [11-14,16-20]. The extra-Ni model $\left(\mathrm{Li}_{26} \mathrm{Ni}\right) \mathrm{Ni}_{27} \mathrm{O}_{54}$ also exhibits a conducting behavior. In the antisite model $\left(\mathrm{Li}_{26} \mathrm{Ni}\right)\left(\mathrm{Ni}_{26} \mathrm{Li}\right) \mathrm{O}_{54}$, the band gap of $0.40 \mathrm{eV}$ is consistent with the experimental data $(0.2 \mathrm{eV}[13]$ and $0.5 \mathrm{eV}$ [14]). Models with different $\mathrm{Ni} / \mathrm{Li}$ concentrations also exhibited

\footnotetext{
${ }^{1}$ School of Advanced Materials, Peking University Shenzhen Graduate School, Shenzhen 518055, China

2 Fujian Science \& Technology Innovation Laboratory for Energy Devices of China (21C-LAB), Ningde 352100, China

† These authors contributed equally to this work.

* Corresponding authors (emails: panfeng@pkusz.edu.cn (Pan F); zhengjx@pkusz.edu.cn (Zheng J))
} 

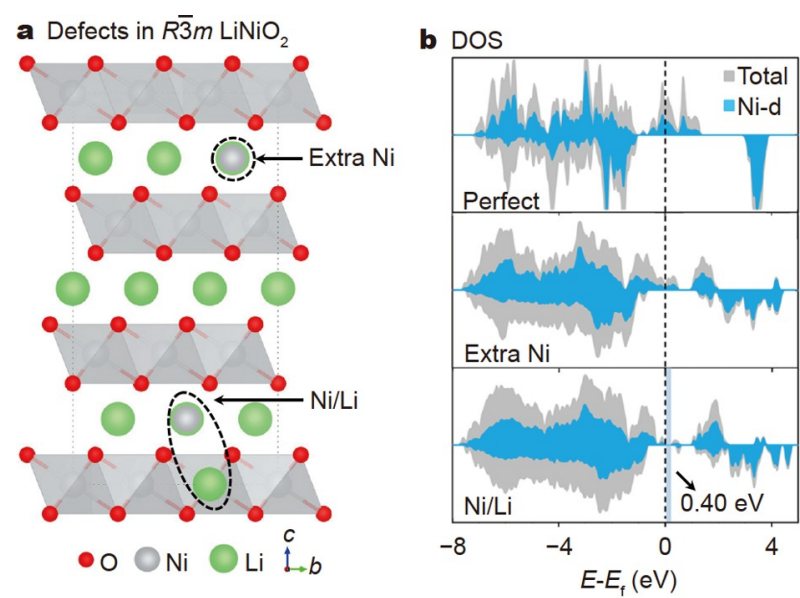

Figure 1 (a) Illustration of defects in $R \overline{3} m$ LNO. (b) DOS of various LNO.

band gaps of $\sim 0.5 \mathrm{eV}$ (Table S1) instead of conducting behaviors. Since the defect concentration was experimentally reported as $\sim 3 \%$ [13], we focused on $\left(\mathrm{Li}_{26} \mathrm{Ni}\right)\left(\mathrm{Ni}_{26} \mathrm{Li}\right) \mathrm{O}_{54}$, whose concentration was $3.7 \%$. The antisite LNO $\left(-333.09 \mathrm{meV}\right.$ f.u. ${ }^{-1}$ relative to $R \overline{3} \mathrm{~m})$ is a thermodynamically stable structure since its energy is lower than that of $R \overline{3} \mathrm{~m}$ LNO and close to that of $C 2 / \mathrm{m}$ LNO $\left(-419.38 \mathrm{meV}\right.$ f.u. ${ }^{-1}$ relative to $\left.R \overline{3} \mathrm{~m}\right)$, which is another disputed possibility but exhibits CJTD [22].

$\mathrm{Ni}^{3+}$ bears the $\mathrm{t}_{2 \mathrm{~g}}{ }^{6} \mathrm{e}_{\mathrm{g}}{ }^{1}$ electronic configuration, which is $\mathrm{JT}$ active. Fig. 2 profiles the Jahn-Teller distortion (JTD) of $R \overline{3} m$ LNO without or with $\mathrm{Ni} / \mathrm{Li}$. The ideal LNO shows neither a CJTD nor an LJTD. Chung et al. [8] suggested that LNO is in a trimer ordering with three equivalent JTD directions, by neutron diffraction. However, some theoretical and experimental studies suggested that a local or mesoscale trimer structure may exist but the possibility of a long-range trimer ordering should be excluded since it is unstable [22,30,32]. As far as we are aware, although the specific form of distortion is still under debate, no report has denied that JTD occurs locally with three kinds of oriented JT orbitals in LNO. This has been exactly observed in our antisite LNO. Besides, this is another reason to exclude $P 2_{1} / c$ LNO, which bears a zigzag JTD [22,29-31]. Only partial $\mathrm{NiO}_{6}$ octahedra of the antisite LNO distort with three kinds of oriented JT orbitals, and CJTD is absent (Fig. 2b). $\left(\mathrm{Li}_{26} \mathrm{Ni}\right)$ $\left(\mathrm{Ni}_{26} \mathrm{Li}\right) \mathrm{O}_{54}$ possesses $\mathrm{Q}_{2}$ and $\mathrm{Q}_{3}$ symmetrized octahedral modes (Fig. 2c) [50]. Different bond lengths are grouped as long $(\sim 2.08 \AA)$ and short bonds $(\sim 1.95 \AA)$, which are in good agreement with the LJTD data obtained by the neutron diffraction (long bond lengths $\sim 2.05 \AA$, short ones $\sim 1.95 \AA$ ) [8].

It is necessary to determine the charge state of $\mathrm{Ni}$ ions since only $\mathrm{Ni}^{3+}$ is JT-active. Magnetic moments of nickel ions in $\left(\mathrm{Li}_{26} \mathrm{Ni}\right)\left(\mathrm{Ni}_{26} \mathrm{Li}\right) \mathrm{O}_{54}$ are divided into three groups (Fig. 3a), and the projected density of states (PDOS) of Ni ions corresponding to the magnetic moments are illustrated in Fig. $3 \mathrm{~b}$. Ni ions with magnetic moments of $\sim 1.63 \mu_{\mathrm{B}}(25.93 \%), \sim 0.85 \mu_{\mathrm{B}}(55.56 \%)$, and $0.00 \mu_{\mathrm{B}}(18.52 \%)$ favor electronic configurations of $\mathrm{t}_{2 \mathrm{~g}}{ }^{6} \mathrm{e}_{\mathrm{g}}{ }^{2}\left(\mathrm{Ni}^{2+}\right)$, $\mathrm{t}_{2 \mathrm{~g}}{ }^{6} \mathrm{e}_{\mathrm{g}}{ }^{1}\left(\mathrm{Ni}^{3+}\right)$, and $\mathrm{t}_{2 \mathrm{~g}}{ }^{6} \mathrm{e}_{\mathrm{g}}{ }^{0}\left(\mathrm{Ni}^{4+}\right)$, respectively. $\mathrm{Ni}$ ions in various charge states contributed to the total charge balance. We observed that $\mathrm{Ni}^{3+}$ ions correspond to JT ions or orbital orderings, while $\mathrm{Ni}^{4+}$ and $\mathrm{Ni}^{2+}$ correspond to charge orderings (Fig. 3a). The competition between orbital ordering and charge ordering has also been demonstrated by Chen et al. [22]. $\mathrm{Ni}^{4+}$ and $\mathrm{Ni}^{2+}$ are products of the sharp distortion. The intense interactions between $\mathrm{Ni}-3 \mathrm{~d}$ and $\mathrm{O}-2 \mathrm{p}$ orbitals are triggered, resulting in the variation of all $\mathrm{Ni}-\mathrm{O}$ bond lengths in a $\mathrm{NiO}_{6}$ octahedron. Distortions in the $\mathrm{Q}_{2}$ and $\mathrm{Q}_{3}$ modes result in the splitting of $e_{g}$ bands [51]. Both $t_{2 g}$ and $e_{g}$ bands will split under a JTD, but $t_{2 g}$ is fully filled and below the Fermi level; therefore, its splitting will not be discussed herein. Every Ni with a $0.85 \mu_{\mathrm{B}}$ magnetic moment, namely $\mathrm{Ni}^{3+}$, exhibits a normal JTD. Though LNO exhibits partial JTD, every $\mathrm{NiO}_{6}$ octahedron undergoes a distortion, and local orbital ordering is the embodiment of distortions to various extents. Moreover, JTD is not only a characteristic of crystal structures but also the origin of electronic structures, since it causes the splitting of bands and creates band gaps. Besides, such a metal-semiconductor transition along with the orbital ordering in LNO may be related to the spin-Peierls transition, as reported by Hase et al. [52] for
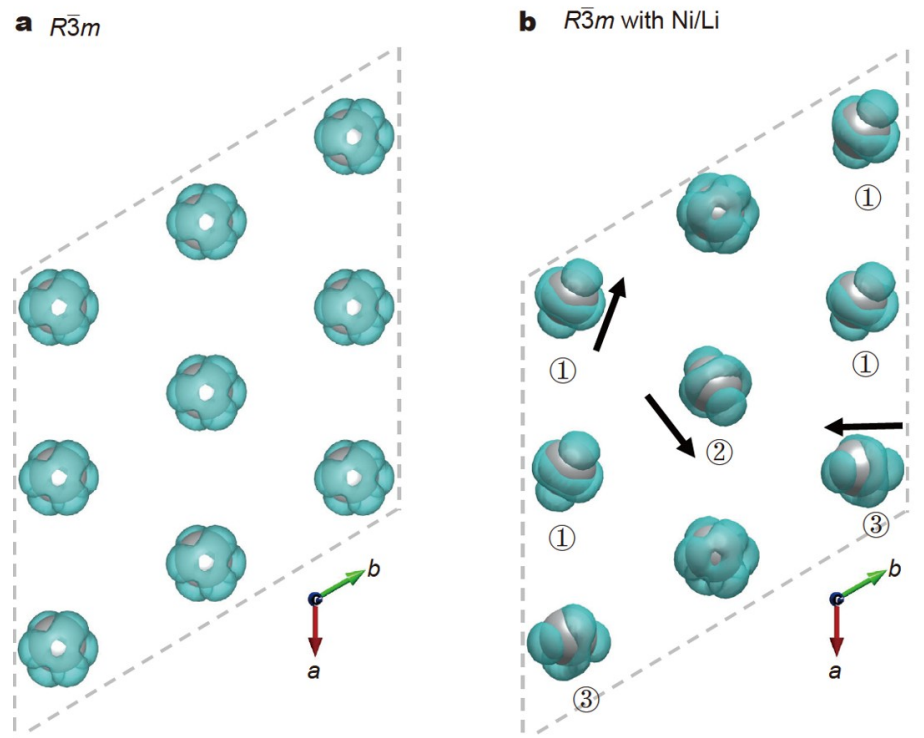

c JTD mode

Q
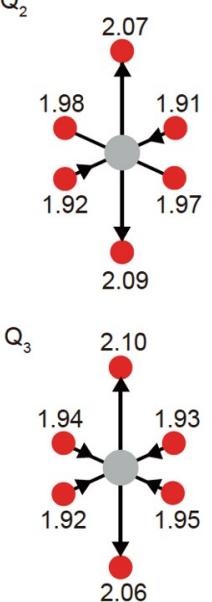

Figure $23 \mathrm{D}$ spin electron density maps of Ni ions in LNO (a) without and (b) with Ni/Li, respectively. The isovalues for the isosurfaces of the spin densities are $0.05 \AA^{-3}$. Arrows in (b) imply lengthened $\mathrm{Ni}-\mathrm{O}$ directions. (c) $\mathrm{Q}_{2}$ and $\mathrm{Q}_{3}$ modes of JTD. 


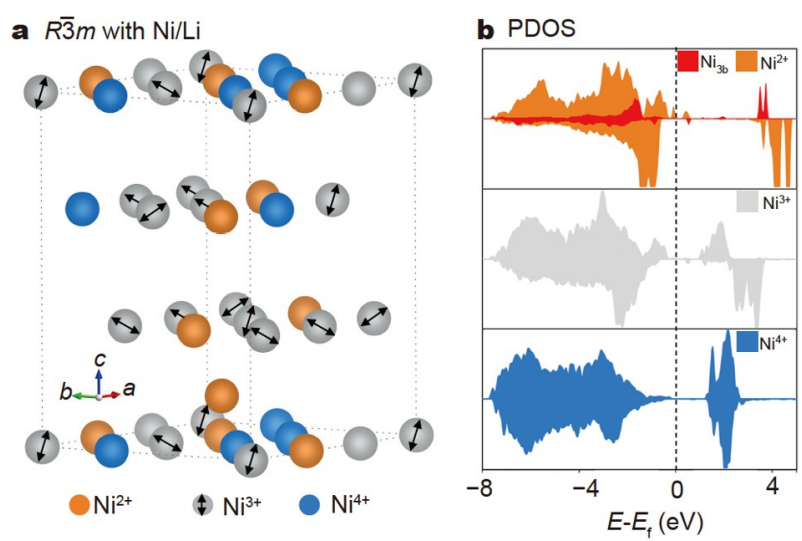

Figure 3 (a) Magnetic moments and (b) PDOS for Ni-d orbitals of corresponding $\mathrm{Ni}$ ions for various magnetic moments of $\mathrm{LNO}$ with $\mathrm{Ni} / \mathrm{Li}$.

\section{$\mathrm{CuGeO}_{3}$}

The $\mathrm{Ni} / \mathrm{Li}$ antisites consist of $\mathrm{Ni}^{2+}$ at $3 \mathrm{~b}$ sites $\left(\mathrm{Ni}^{2+}{ }_{3 \mathrm{~b}}\right)$ and $\mathrm{Li}^{+}$at 3a sites $\left(\mathrm{Li}^{+}{ }_{3 \mathrm{a}}\right)$ (Fig. 1a). We compared $\left(\mathrm{Li}_{26} \mathrm{Ni}\right)\left(\mathrm{Ni}_{26} \mathrm{Li}\right) \mathrm{O}_{54}$ (with $\mathrm{Ni} / \mathrm{Li}$ ) with the other two models: $\left(\mathrm{Li}_{26} \mathrm{Ni}\right) \mathrm{Ni}_{27} \mathrm{O}_{54}$ (with only $\mathrm{Ni}_{3 \mathrm{~b}}{ }^{2+}$ ) and $\mathrm{Li}_{27}\left(\mathrm{Ni}_{26} \mathrm{Li}\right) \mathrm{O}_{54}$ (with only $\mathrm{Li}_{3 \mathrm{a}}^{+}$) (Figs $\mathrm{S} 2$ and $\mathrm{S} 3$ ). $\mathrm{Ni}^{2+} 3 \mathrm{~b}$ and $\mathrm{Li}^{+}{ }_{3 \mathrm{a}}$ affect the $\mathrm{NiO}_{2}$ slabs via the size effect and Coulomb interactions. The disturbance from $\mathrm{Ni}^{2+}{ }_{3 \mathrm{~b}}$ is weak. Based on the Shannon ionic radius [53], $\mathrm{Li}^{+}, \mathrm{Ni}^{2+}$, and $\mathrm{Ni}^{3+}$ bear ionic radii of $0.76,0.69$, and $0.56 \AA$, respectively, and since the ionic radii of $\mathrm{Li}^{+}$and $\mathrm{Ni}^{2+}$ are close, the size effect of $\mathrm{Ni}^{2+}{ }_{3 \mathrm{~b}}$ is faint. Moreover, though $\mathrm{Ni}^{2+}{ }_{3 \mathrm{~b}}$ carries more charge than $\mathrm{Li}^{+}{ }_{3 \mathrm{~b}}$, the Coulomb interaction can hardly be considered, as interplanar $\left(\mathrm{NiO}_{6}\right)_{3 \mathrm{~b}}$ and $\left(\mathrm{NiO}_{6}\right)_{3 \mathrm{a}}$ octahedra are corner-sharing (Fig. S3c) and the Coulomb repulsion between $\mathrm{Ni}^{3+}{ }_{3 a}$ and $\mathrm{Ni}^{2+}{ }_{3 b}$ is screened by the shared $\mathrm{O}$ ion. Thus, $\left(\mathrm{Li}_{26} \mathrm{Ni}\right) \mathrm{Ni}_{27} \mathrm{O}_{54}$ has the smallest JTD index (definition in the SI Sect. C) of $\mathrm{NiO}_{6}$ octahedra and exhibits conducting behavior (Figs S2b and S3d). Next, the effects of $\mathrm{Li}^{+}{ }_{3 \mathrm{a}}$ in $R \overline{3} \mathrm{~m}$ LNO was further confirmed by a pure $\mathrm{Li}$-doping model, $\mathrm{Li}_{27}\left(\mathrm{Ni}_{26} \mathrm{Li}\right) \mathrm{O}_{54} \cdot \mathrm{Li}^{+}{ }_{3 \mathrm{a}}$ will drastically disturb $\mathrm{NiO}_{2}$ slabs via both $\mathrm{O}$ and $\mathrm{Ni}$ ions (Fig. 4). Since $\mathrm{Li}^{+}$is larger than $\mathrm{Ni}^{3+}, \mathrm{Li}^{+}{ }_{3 \mathrm{a}}$ disturbs neighboring octahedra via the connected $\mathrm{O}$ ions. Then, $\mathrm{Ni}^{3+}{ }_{3 a}$ witnesses a decrease in the $\mathrm{Ni}^{3+}{ }_{3 \mathrm{a}}-\mathrm{O}$ bond lengths and an increase in the $\mathrm{O}-\mathrm{Ni}^{3+}{ }_{3 \mathrm{a}}-\mathrm{O}$ bond angle, as the intraplanar $\mathrm{NiO}_{6}$ and $\mathrm{LiO}_{6}$ octahedra are edgesharing. Moreover, since $\mathrm{NiO}_{2}$ layers consist of edge-sharing octahedra, there is considerable Coulomb repulsion between the cations. $\mathrm{Li}^{+}$carries less charge than $\mathrm{Ni}^{3+}$ and the exclusion is weaker; thus, $\mathrm{Ni}^{3+}{ }_{3 \mathrm{a}}$ ions around $\mathrm{Li}^{+}{ }_{3 \mathrm{a}}$ deviate from their original sites. Therefore, $\mathrm{Li}_{27}\left(\mathrm{Ni}_{26} \mathrm{Li}\right) \mathrm{O}_{54}$ has the largest JTD index (Fig. S3d) and band gap. $\mathrm{Li}^{+}{ }_{3 a}$ substantially affects the determining factors of the JTD and band gap in $R \overline{3} \mathrm{~m}$ LNO.

On the other hand, $\mathrm{Li}_{3 \mathrm{a}}$ is rigid and will obstruct the cooperation of JTD. In $\mathrm{LNO}, \mathrm{NiO}_{6}$ octahedra share edges, and thus, they do not independently distort [54]. When $\mathrm{Ni} / \mathrm{Li}$ are introduced in the ideal $\mathrm{C} 2 / m \mathrm{LNO}$, the rigid $\mathrm{Li}^{+}{ }_{3 \mathrm{a}} \mathrm{O}_{6}$ octahedra reduce the crystal symmetry; therefore, the correlation of individual active $\mathrm{Ni}^{3+}$ centers is disrupted, and the elongations of $\mathrm{Ni}^{3+} \mathrm{O}_{6}$ octahedra do not occur in a uniform direction; rather, three distorted orientations are observed (Figs 2 and 4). The JTD index of $\mathrm{NiO}_{6}$ octahedra, particularly near the $\mathrm{Ni} / \mathrm{Li}$, are also reduced (Fig. S4). Thus, the $\mathrm{Ni} / \mathrm{Li}$ can trigger the JTD in $R \overline{3} m$ LNO on one hand, but hamper the further evolution into CJTD $(\mathrm{C} 2 / \mathrm{m} \mathrm{LNO})$ on the other hand, by breaking the long-range

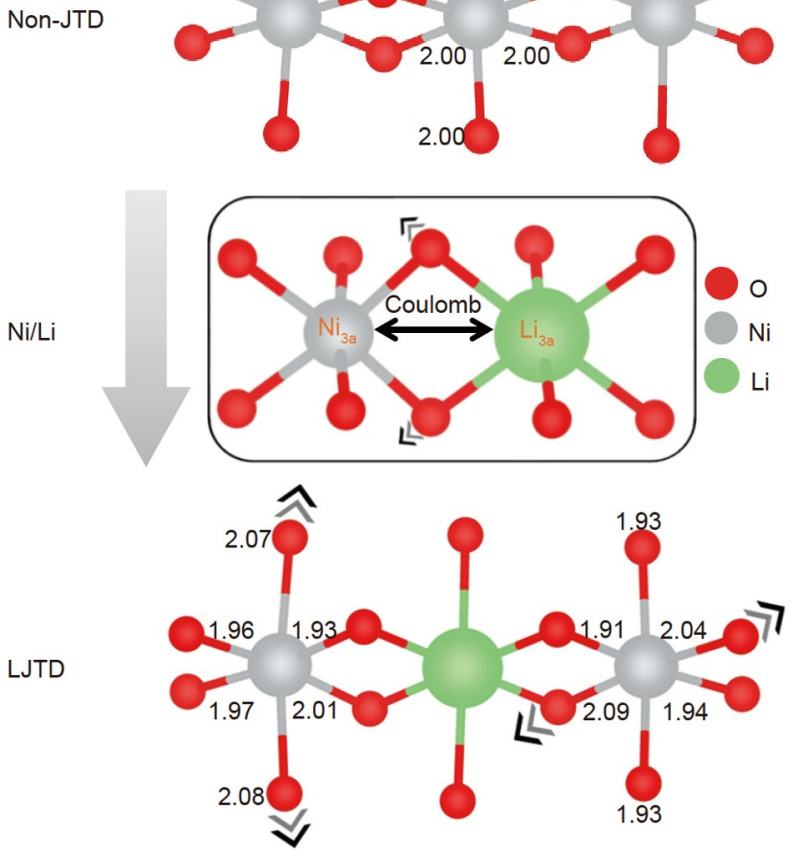

Figure 4 Schematic of the $\mathrm{Li}_{3 \mathrm{a}}$ effects.

interaction similar to the interfacial effects in $\mathrm{LiMnO}_{2}$ as reported by Zhu et al. [55], ultimately resulting in LJTD with a subtle balance between the charge ordering and orbital ordering. By contrast, unlike $\mathrm{Ni} / \mathrm{Li}$ antisites in $\mathrm{LNO}, \mathrm{Ni} / \mathrm{Na}$ antisites in NNO are not feasible from the thermodynamic perspective, and the long-range interaction remains, leading to CJTD and a stable $\mathrm{C} 2 / \mathrm{m}$ state for NNO (detailed discussions in the SI Sect. D).

To summarize, using hybrid density functional calculations, we demonstrated that $\mathrm{Ni} / \mathrm{Li}$ antisites are responsible for the local orbital ordering of $\mathrm{Ni}^{3+}$ in layered LNO, which is in excellent agreement with the experimental data with regards to the LJTD and the small band gap of $\sim 0.5 \mathrm{eV}$. This can be attributed to the competition between the charge ordering and orbital ordering in LNO, which attains a subtle balance after the $\mathrm{Ni} / \mathrm{Li}$ antisites are introduced. Therefore, based on the results of this study, we propose that $\mathrm{Ni} / \mathrm{Li}$ antisites, which have been neglected for a long time in theoretical calculations, deserve more attention in future studies related to the properties of LNO.

Received 2 November 2021; accepted 23 December 2021; published online 27 January 2022

1 Myung ST, Maglia F, Park KJ, et al. Nickel-rich layered cathode materials for automotive lithium-ion batteries: Achievements and perspectives. ACS Energy Lett, 2016, 2: 196-223

$2 \mathrm{Xu}$ J, Lin F, Doeff MM, et al. A review of Ni-based layered oxides for rechargeable Li-ion batteries. J Mater Chem A, 2017, 5: 874-901

3 Liu W, Oh P, Liu X, et al. Nickel-rich layered lithium transition-metal oxide for high-energy lithium-ion batteries. Angew Chem Int Ed, 2015, 54: 4440-4457

4 Li W, Song B, Manthiram A. High-voltage positive electrode materials for lithium-ion batteries. Chem Soc Rev, 2017, 46: 3006-3059

5 Arai $\mathrm{H}$. Characterization and cathode performance of $\mathrm{Li}_{1-x} \mathrm{Ni}_{1+x} \mathrm{O}_{2}$ prepared with the excess lithium method. Solid State Ion, 1995, 80: 


\section{1-269}

6 Delmas C, Ménétrier M, Croguennec L, et al. Lithium batteries: A new tool in solid state chemistry. Int J Inorg Mater, 1999, 1: 11-19

7 Li W, Reimers J, Dahn J. In situ X-ray diffraction and electrochemical studies of $\mathrm{Li}_{1-x} \mathrm{NiO}_{2}$. Solid State Ion, 1993, 67: 123-130

8 Chung $\mathrm{JH}$, Proffen T, Shamoto $\mathrm{S}$, et al. Local structure of $\mathrm{LiNiO}_{2}$ studied by neutron diffraction. Phys Rev B, 2005, 71: 064410

9 Bianchini M, Roca-Ayats M, Hartmann P, et al. There and back againThe journey of $\mathrm{LiNiO}_{2}$ as a cathode active material. Angew Chem Int Ed, 2019, 58: 10434-10458

10 Goodenough JB, Wickham DG, Croft WJ. Some magnetic and crystallographic properties of the system $\mathrm{Li}^{+}{ }_{x} \mathrm{Ni}^{++}{ }_{1-2 x} \mathrm{Ni}^{+++}{ }_{1-x} \mathrm{O}$. J Phys Chem Solids, 1958, 5: 107-116

11 Galakhov VR, Kurmaev EZ, Uhlenbrock S, et al. Electronic structure of $\mathrm{LiNiO}_{2}, \mathrm{LiFeO}_{2}$ and $\mathrm{LiCrO}_{2}$ : X-ray photoelectron and X-ray emission study. Solid State Commun, 1995, 95: 347-351

12 Hirota K, Nakazawa Y, Ishikawa M. Magnetic properties of the $S=1 / 2$ antiferromagnetic triangular lattice $\mathrm{LiNiO}_{2}$. J Phys-Condens Matter, 1991, 3: 4721-4730

13 Kanno R, Kubo H, Kawamoto Y, et al. Phase relationship and lithium deintercalation in lithium nickel oxides. J Solid State Chem, 1994, 110: 216-225

14 Molenda J. Structural, electrical and electrochemical properties of $\mathrm{LiNiO}_{2}$. Solid State Ion, 2002, 146: 73-79

15 Van Houten S. Semiconduction in $\mathrm{Li}_{x} \mathrm{Ni}_{1-x} \mathrm{O}$. J Phys Chem Solids, 1960 , 17: 7-17

16 Momeni M, Yousefi Mashhour H, Kalantarian MM. New approaches to consider electrical properties, band gaps and rate capability of samestructured cathode materials using density of states diagrams: Layered oxides as a case study. J Alloys Compd, 2019, 787: 738-743

17 Anisimov VI, Zaanen J, Andersen OK. Band theory and Mott insulators: Hubbard $U$ instead of Stoner I. Phys Rev B, 1991, 44: 943-954

18 Evarestov RA, Veryazov VA, Tupitsyn II, et al. The electronic structure of crystalline nickel oxides. J Electron Spectr Relat Phenomena, 1994, 68: 555-563

19 Korotin DM, Novoselov D, Anisimov VI. Paraorbital ground state of the trivalent $\mathrm{Ni}$ ion in $\mathrm{LiNiO}_{2}$ from DFT+DMFT calculations. Phys Rev B, 2019, 99: 045106

20 Chakraborty A, Dixit M, Aurbach D, et al. Predicting accurate cathode properties of layered oxide materials using the scan meta-GGA density functional. npj Comput Mater, 2018, 4: 60

21 Chen Z, Zou H, Zhu X, et al. First-principle investigation of JahnTeller distortion and topological analysis of chemical bonds in $\mathrm{LiNiO}_{2}$. J Solid State Chem, 2011, 184: 1784-1790

22 Chen H, Freeman CL, Harding JH. Charge disproportionation and Jahn-Teller distortion in $\mathrm{LiNiO}_{2}$ and $\mathrm{NaNiO}_{2}$ : A density functional theory study. Phys Rev B, 2011, 84: 085108

23 Chappel E, Núñez-Regueiro MD, Chouteau G, et al. Study of the ferrodistorsive orbital ordering in $\mathrm{NaNiO}_{2}$ by neutron diffraction and submillimeter wave ESR. Eur Phys J B, 2000, 17: 615-622

24 Rougier A, Delmas C, Chadwick AV. Non-cooperative Jahn-Teller effect in $\mathrm{LiNiO}_{2}$ : An EXAFS study. Solid State Commun, 1995, 94: 123127

25 Nakai I, Takahashi K, Shiraishi Y, et al. Study of the Jahn-Teller distortion in $\mathrm{LiNiO}_{2}$, a cathode material in a rechargeable lithium battery, by in situ X-ray absorption fine structure analysis. J Solid State Chem, 1998, 140: 145-148

26 Delmas C, Pérès JP, Rougier A, et al. On the behavior of the $\mathrm{Li}_{x} \mathrm{NiO}_{2}$ system: An electrochemical and structural overview. J Power Sources, 1997, 68: 120-125

27 Borgers PF, Enz U. Metamagnetism of $\mathrm{NaNiO}_{2}$. Solid State Commun, 1966, 4: 153-157

28 Meskine H, Satpathy S. Electronic structure and magnetism in sodium nickelate: Density-functional and model studies. Phys Rev B, 2005, 72: 224423

29 Sicolo S, Mock M, Bianchini M, et al. And yet it moves: $\mathrm{LiNiO}_{2}$, a dynamic Jahn-Teller system. Chem Mater, 2020, 32: 10096-10103

30 Radin MD, Van der Ven A. Simulating charge, spin, and orbital ordering: Application to Jahn-Teller distortions in layered transition- metal oxides. Chem Mater, 2018, 30: 607-618

31 Das H, Urban A, Huang W, et al. First-principles simulation of the ( $\mathrm{Li}-$ $\mathrm{Ni}$-vacancy)O phase diagram and its relevance for the surface phases in Ni-rich Li-ion cathode materials. Chem Mater, 2017, 29: 7840-7851

32 Cao J, Zou H, Guo C, et al. Local trimer orbital ordering in $\mathrm{LiNiO}_{2}$ studied by quantitative convergent beam electron diffraction technique. Solid State Ion, 2009, 180: 1209-1214

33 Petit L, Stocks GM, Egami T, et al. Ground state valency and spin configuration of the Ni ions in nickelates. Phys Rev Lett, 2006, 97: 146405

34 Koyama Y, Arai H, Tanaka I, et al. Defect chemistry in layered $\mathrm{LiMO}_{2}$ $\left(\mathrm{M}=\mathrm{Co}, \mathrm{Ni}, \mathrm{Mn}\right.$, and $\left.\mathrm{Li}_{1 / 3} \mathrm{Mn}_{2 / 3}\right)$ by first-principles calculations. Chem Mater, 2012, 24: 3886-3894

35 Toma T, Maezono R, Hongo K. Electrochemical properties and crystal structure of $\mathrm{Li}^{+} / \mathrm{H}^{+}$cation-exchanged $\mathrm{LiNiO}_{2}$. ACS Appl Energy Mater, 2020, 3: 4078-4087

36 Radin MD, Thomas JC, Van der Ven A. Order-disorder versus displacive transitions in Jahn-Teller active layered materials. Phys Rev Mater, 2020, 4: 043601

37 Uchigaito $\mathrm{H}$, Udagawa $\mathrm{M}$, Motome Y. Mean-field study of charge, spin, and orbital orderings in triangular-lattice compounds $\mathrm{ANiO}_{2}(\mathrm{~A}=\mathrm{Na}$, Li, Ag). J Phys Soc Jpn, 2011, 80: 044705

38 Hirano A. Relationship between non-stoichiometry and physical properties in $\mathrm{LiNiO}_{2}$. Solid State Ion, 1995, 78: 123-131

39 Rougier A, Gravereau P, Delmas C. Optimization of the composition of the $\mathrm{Li}_{1-z} \mathrm{Ni}_{1+z} \mathrm{O}_{2}$ electrode materials: Structural, magnetic, and electrochemical studies. J Electrochem Soc, 1996, 143: 1168-1175

40 Yamaura K, Takano M, Hirano A, et al. Magnetic properties of $\mathrm{Li}_{1-x} \mathrm{Ni}_{1+x} \mathrm{O}_{2}(0 \lesssim x \lesssim 0.08)$. J Solid State Chem, 1996, 127: 109-118

41 Zheng J, Teng G, Xin C, et al. Role of superexchange interaction on tuning of $\mathrm{Ni} / \mathrm{Li}$ disordering in layered $\mathrm{Li}\left(\mathrm{Ni}_{x} \mathrm{Mn}_{y} \mathrm{Co}_{z}\right) \mathrm{O}_{2}$. J Phys Chem Lett, 2017, 8: 5537-5542

42 Kim JM, Chung HT. The first cycle characteristics of $\mathrm{Li}\left[\mathrm{Ni}_{1 / 3} \mathrm{Co}_{1 / 3}\right.$ $\left.\mathrm{Mn}_{1 / 3}\right] \mathrm{O}_{2}$ charged up to $4.7 \mathrm{~V}$. Electrochim Acta, 2004, 49: 937-944

43 Venkatraman S, Manthiram A. Structural and chemical characterization of layered $\mathrm{Li}_{1-}{ }_{x} \mathrm{Ni}_{1-y} \mathrm{Mn}_{y} \mathrm{O}_{2-\delta}(y=0.25$ and 0.5 , and $0 \leq(1-x) \leq$ 1) oxides. Chem Mater, 2003, 15: 5003-5009

44 Gao A, Sun Y, Zhang Q, et al. Evolution of $\mathrm{Ni} / \mathrm{Li}$ antisites under the phase transition of a layered $\mathrm{LiNi}_{1 / 3} \mathrm{Co}_{1 / 3} \mathrm{Mn}_{1 / 3} \mathrm{O}_{2}$ cathode. J Mater Chem A, 2020, 8: 6337-6348

45 Chen H, Dawson JA, Harding JH. Effects of cationic substitution on structural defects in layered cathode materials $\mathrm{LiNiO}_{2}$. J Mater Chem A, 2014, 2: 7988-7996

46 Wang D, Kou R, Ren Y, et al. Synthetic control of kinetic reaction pathway and cationic ordering in high-Ni layered oxide cathodes. Adv Mater, 2017, 29: 1606715

47 Ohzuku T, Ueda A, Nagayama M. Electrochemistry and structural chemistry of $\mathrm{LiNiO}_{2}(R 3 m)$ for 4 volt secondary lithium cells. J Electrochem Soc, 1993, 140: 1862-1870

48 Dahn J. Structure and electrochemistry of $\mathrm{Li}_{1 \pm y} \mathrm{NiO}_{2}$ and a new $\mathrm{Li}_{2} \mathrm{NiO}_{2}$ phase with the $\mathrm{Ni}(\mathrm{OH})_{2}$ structure. Solid State Ion, 1990, 44: 87-97

49 Reynaud F, Mertz D, Celestini F, et al. Orbital frustration at the origin of the magnetic behavior in $\mathrm{LiNiO}_{2}$. Phys Rev Lett, 2001, 86: 3638-3641

50 Sturge MD. The Jahn-Teller Effect in Solids. New York: Academic Press, 1968

51 Van Vleck JH. The Jahn-Teller effect and crystalline stark splitting for clusters of the form $\mathrm{XY}_{6}$. J Chem Phys, 1939, 7: 72-84

52 Hase M, Terasaki I, Uchinokura K. Observation of the spin-Peierls transition in linear $\mathrm{Cu}^{2+}$ (spin-1/2) chains in an inorganic compound $\mathrm{CuGeO}_{3}$. Phys Rev Lett, 1993, 70: 3651-3654

53 Shannon R. Revised effective ionic radii and systematic studies of interatomic distances in halides and chalcogenides. Acta Crystallographica Section A, 1976, 32: 751-767

54 Marianetti CA, Morgan D, Ceder G. First-principles investigation of the cooperative Jahn-Teller effect for octahedrally coordinated transitionmetal ions. Phys Rev B, 2001, 63: 224304

55 Zhu X, Meng F, Zhang Q, et al. $\mathrm{LiMnO}_{2}$ cathode stabilized by interfacial orbital ordering for sustainable lithium-ion batteries. Nat Sustain, 2021, 4: 392-401 
Acknowledgements The study was financially supported by the Starting Fund of Peking University Shenzhen Graduate School and Fujian Science \& Technology Innovation Laboratory for Energy Devices of China (21C-LAB), and the National Natural Science Foundation of China (12174162). The authors thank Prof. Qihang Liu from Southern University of Science and Technology for the helpful discussions.

Author contributions Zheng J supervised this work. Lin W and Ye Y designed the idea and wrote the paper. Lin $\mathrm{W}, \mathrm{Ye} \mathrm{Y}$, and Chen $\mathrm{T}$ performed the data analysis and visualization. All authors contributed to the general discussion and conceptualization.

Conflict of interest The authors declare that they have no conflict of interest.

Supplementary information Experimental details and supporting data are available in the online version of the paper.

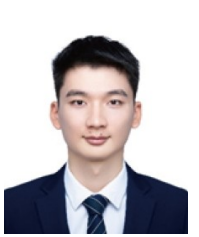

Weicheng Lin received his BSc degree from Northeastern University in 2019. Now he is a master student under the supervision of Prof. Jiaxin Zheng at Peking University. His research interests include computational materials and energy materials.

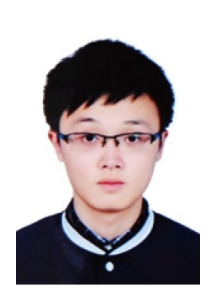

Yaokun Ye received his BSc degree from Jinan University in 2018. Now he is a PhD candidate under the supervision of Prof. Jiaxin Zheng at Peking University. His research interests include computational materials and energy materials.

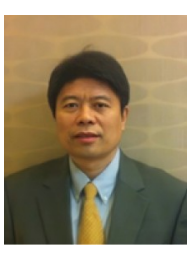

Feng Pan is the Chair-Professor, Founding Dean of School of Advanced Materials, Peking University Shenzhen Graduate School. He received his PhD from the Department of P\&A Chemistry, University of Strathclyde, Glasgow, U.K., receiving the "Patrick D. Ritchie Prize" for the best $\mathrm{PhD}$ in 1994. Prof. Pan has been engaged in the fundamental research and product development of novel optoelectronic and energy storage materials and devices.

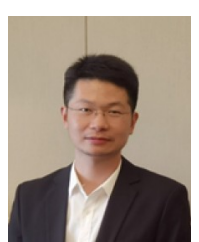

Jiaxin Zheng received his $\mathrm{PhD}$ in condensed physics from Peking University in 2013. He is currently working as an Associate Professor at the School of Advanced Materials, Peking University. His research interests include computational materials and energy materials.

\section{层状 $\mathrm{LiNiO}_{2}$ 中的缺陷调制Jahn-Teller效应}

林伟成 ${ }^{1 \dagger}$, 叶耀坤 ${ }^{1 \dagger}$, 陈涛文 ${ }^{1}$, 蒋耀 ${ }^{2}$, 欧阳楚英 ${ }^{2}$, 潘锋 ${ }^{*}$, 郑家新 ${ }^{1,2^{*}}$

摘要 $\mathrm{LiNiO}_{2}$ ( $\mathrm{LNO}$ )基态的晶体结构和电子结构长期以来存在着实验 与理论计算不一致的争议. 实验上观测到 $\mathrm{LNO}$ 是空间群为 $R \overline{3} m$ 的半导 体并且有局部的Jahn-Teller (JT)畸变, 但理论计算却表明它是处于亚 稳态的金属并且没有任何的 $\mathrm{JT}$ 畸变. 本文基于杂化密度泛函理论 HSE06, 首次模拟了与实验等同浓度 $(\sim 3 \%)$ 的 $\mathrm{Ni} / \mathrm{Li}$ 反位缺陷对 $\mathrm{LNO}$ 的 影响, 发现缺陷能够有效调控LNO中的JT效应. 在 $\mathrm{LNO}$ 中引入 $\mathrm{Ni} / \mathrm{Li}$ 反 位缺陷后, 其结构发生了局部的JT畸变, 并且其带隙值约为 $0.5 \mathrm{eV}$, 这 些计算结果都和实验现象非常吻合. $\mathrm{Ni} / \mathrm{Li}$ 反位通过粒径效应和库伦作 用, 既能诱发 $\mathrm{JT}$ 畸变, 又能阻碍畸变之间的协同作用, 避免相变到 $C 2 / m$, 而只产生局部的JT畸变. 本文提出了一种新的策略来解释 LNO基态晶 体结构和电子结构长期以来的争议, 对推动富镍层状材料的设计和应 用具有重要意义. 